\title{
Effect Assessment of Ecological Construction in China from 2008 to 2014
}

\author{
Chen $\mathrm{Li}^{1 *}$, Baolong Yuan ${ }^{2}$, Yuepeng Zhang ${ }^{1}$ \\ ${ }^{1}$ School of Business, Central South University, Changsha, China \\ ${ }^{2}$ School of Business, Central South University of Forestry and Technology, Changsha, China
}

Received: 17 December 2017

Accepted: 28 February 2018

\begin{abstract}
In this paper, we assess the effect of ecological construction in China during 2008 to 2014. The effect of ecological construction is divided into green economy, green society, and green environment. A network data envelopment analysis (DEA) is employed to measure the total level of ecological construction in China and each region. According to the results, we find that the total level of ecological construction of China is still low. At the same time, there are also significant differences between regions. The regions with a developed economy have better performance on ecological construction. We also find that environmental protection is still the weak link of ecological construction in various regions. Hence, local governments still need to develop a green economy and increase investment on environmental protection in the future - especially on pollution control facilities.
\end{abstract}

Keywords: Chinese ecological construction, green economy, green society, green environment, network data envelopment analysis (network DEA)

\section{Introduction}

China has enjoyed accelerated economic growth successively over the past twenty years. However, during this period China has suffered from acid rain, haze, land pollution, and river pollution. The ecological issue has become a bottleneck impending sustainable development. In 2007, the Chinese government implemented a national strategy on ecological construction. This strategy includes three aspects: green economy, green society, and green environment. The green economy means that all regions should save energy, reduce pollutant emissions, and improve the contribution of science and technology to economic

*e-mail: terry_csu@sina.com development. Green society means that the living departments should save water and energy as well as increase investment in education and health insurance. The green environment means that all regions will increase investment in infrastructure for improving pollutant treatment capacity as well as the green level. Through these approaches, China will build a resourceconserving and environmentally friendly country in the next decade.

Usually, eco-efficiency is defined as creating more value and consuming less resources [1] or maximizing the performance between the economy and the environment [2]. Eco-efficiency was first applied in developed countries or regions. Korhonen and Luptacik discussed environmental policy based on the notion of eco-efficiency. They decomposed efficiency into two parts: technical efficiency and ecological efficiency, 
and measured the eco-efficiency of 24 power plants in a European country [3]. Cote et al. described a study undertaken by the Eco-Efficiency Centre of the levels of eco-efficiency demonstrated by small and medium enterprises in Nova Scotia. Their study concluded that levels of eco-efficiency were quite low among businesses in different sectors, and furthermore that more work was needed to find appropriate tools for micro and small businesses that can be more widely used [4]. Recently, more and more researchers in developed countries have transferred their attention to production processes. Their studies began to focus on eco-design of products [5-6], production project [7], and quality management based on eco-efficiency [8] and eco-efficiency evaluation [9-11]. In developing countries, China's issue of eco-efficiency has received more attention. Wang et al. studied the relationship between environmental regulations and eco-efficiency, Shandong Province's pulp and paper industry. They found that stricter regulation could improve most of the efficiency indicators [12]. Some studies applied the weighted Russell directional distance model or directional slack-based measure (DSBM) to measure eco-efficiency in the Chinese heavy pollution industry [13-14]. Some studies found an N-shaped relationship that exists between urbanization and urban eco-efficiency in 281 cities of China during 2006-2013. Urban eco-efficiency, measured by super-efficiency data envelopment analysis, first increases, then declines, and then increases again with the improvement of urbanization [15]. A similar study found that the overall eco-efficiency of China was low and the eco-efficiency performances of a majority of the municipalities and sub-provincial (M\&S) cities were better than those of the prefecture-level cities based on 262 cities in China during the period of 2005-2012 [16]. There are many studies on China's regional ecology. However, we found that the research on region eco-efficiency in China was still relatively less.

In this paper, we use eco-efficiency to assess the effect of ecological construction in China. Ecoefficiency is divided into three parts: green economy, green society, and green environment. A network data envelopment analysis (network-DEA) is applied to measure eco-efficiency for finding the internal link between different parts. Section 2 is the methods in this article. We present our results and discussion in Section 3. In Section 4 we present our conclusions based on results and discussion.

\section{Material and Methods}

\section{Network DEA}

DEA is a useful tool for evaluating relative performance of homogeneous decision-making units (DMUs). DEA treats the intermediate process as a black box, meaning that it imposes minimal assumptions on the internal transformation processes [17]. However, in some systems, the production process of the DMU is divided into sub-processes that intermediate products are outputs of one sub-process and become the inputs of another sub-process [18]. In 1996, Fare and Grosskopf developed a DEA framework and introduced the network DEA in 2000 [19-20]. Since then, more and more researchers have developed many DEA models to explore internal links among each DMU for improving accuracy of efficiency assessment [21-23]. Compared to the previous DEA models, the network DEA model eliminates the drawbacks of the traditional DEA model, which is the neglect of internal linking activities [24]. Meanwhile, this model considers the internal relationship between outputs and inputs in different DMUs. It integrates all DMUs dynamically and presents more practical and precise results than the traditional models. In this paper, we introduce the network system presented by Tone and Tsutsui [25] and divide ecoefficiency into three divisions. Fig. 1 shows three divisions of eco-efficiency and internal links among different divisions.

Assume that there are $M$ DMUs $(M=1, \ldots, m)$ consisting of $N$ divisions $(N=1, \ldots, n)$. We set $d_{n}$ and $s_{n}$ as the numbers of inputs and outputs to Division $n$. We defineas $x_{m}{ }^{n}$ the input to $\mathrm{DMU}_{\mathrm{m}}$ at Division $n$, as the output from $\mathrm{DMU}_{\mathrm{m}}$ at Division $n, y_{m}{ }^{n}$ and $\operatorname{link}_{n, n-1}$ as the linking internal transfer from division $n$ to division $n-1$ - where $x_{m}{ }^{n} \in R^{d_{n}}, y_{m}{ }^{n} \in R^{s_{n}}, \operatorname{link}_{m}{ }^{(n, n-1)} \in R^{(n, n-1)}$, $M=1, \ldots, m$ and $N=1, \ldots, n$. Hence, the production

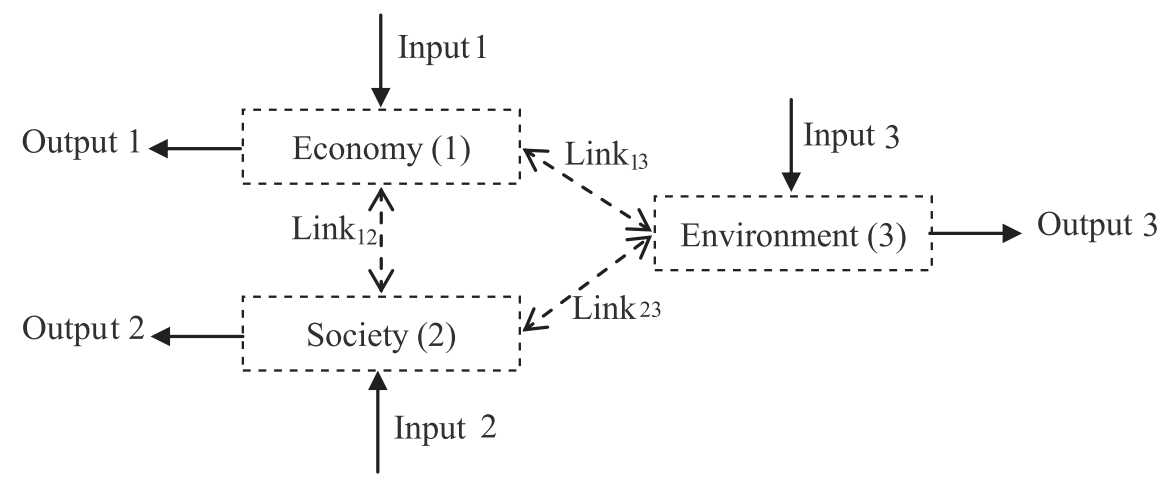

Fig. 1. Network system of eco-efficiency. 
possibility set $\left(x_{m}{ }^{n}, y_{m}{ }^{n}, \operatorname{link}_{m}{ }^{(n, n-1)}\right)$ could be denoted by:

$$
\begin{gathered}
x^{n} \geq \sum_{m=1}^{m} \omega_{m}^{n} x_{m}^{n} \\
y^{n} \leq \sum_{m=1}^{m} \omega_{m}^{n} y_{m}^{n} \\
\operatorname{link} k^{(n, n-1)}=\sum_{m=1}^{m} \omega_{m}^{n} \operatorname{lin} k_{m}^{(n, n-1)} \\
\sum_{m=1}^{i} \omega_{m}^{n}=1
\end{gathered}
$$

...where $m=1, \ldots, i$ and $n=1, \ldots, j$. Here, we introduce slack vectors. The $\mathrm{DMU}_{\mathrm{M}}(\mathrm{M}=1, \ldots, \mathrm{m})$ can be represented by:

$$
\begin{aligned}
& X^{n}=\omega^{n} x_{m}^{n}+s^{n-} \\
& Y^{n}=\omega^{n} y_{m}^{n}-s^{n+}
\end{aligned}
$$

$\ldots$ where $s^{n-} \geq 0, s^{n+} \geq 0, X^{n}=\left(x_{1}{ }^{n}, \ldots, x_{m}{ }^{n}\right) \in R$, and $Y^{n}=\left(y_{1}{ }^{n}, \ldots, y_{m}{ }^{n}\right) \in R$. We adopt input-oriented results to evaluate eco-efficiency. We denoteas the total ecoefficiency of the $\mathrm{DMU}_{\mathrm{m}}$. If $\theta^{\prime}=1$, the $\mathrm{DMU}_{\mathrm{m}}$ is totally efficient. Therefore, we evaluate the eco-efficiency of $\mathrm{DMU}_{\mathrm{m}}$ by solving the linear program below:

$$
\theta_{m}^{t}=\min _{\omega^{n}, s^{n}} \sum_{n=1}^{n} \lambda^{n}\left[1-\frac{1}{t_{n}}\left(\sum_{i=1}^{t} \frac{s_{m}^{n-}}{x_{m}^{n}}\right)\right]
$$

...where $\sum_{n=1}^{n} \lambda^{n}=1, \lambda^{n} \geq 0$, represents the number of inputs of the Nth division, andis the relative weight of the Nth Division and calculated according to Copper et al. [26]. We define the efficiency of Nth division as:

$$
\theta_{n}^{t}=1-\frac{1}{t_{n}}\left(\sum_{i=1}^{t} \frac{s_{m}^{n-}}{x_{m}^{n}}\right)
$$

$\theta_{n}^{\prime}$ is a divisional efficiency index. When $\theta_{n}^{\prime}=1$, it means totally efficient of Nth division.

\section{Data}

Table 1 shows statistical analysis to the data used. The data set consists of the economy, society, and environment. The data set comes from China Statistical Yearbook, China Energy Statistical Yearbook, China

\begin{tabular}{|c|c|c|c|}
\hline Index & Max & Min & Avg \\
\hline $\begin{array}{l}\text { Energy for industry } \\
\qquad\left(10^{4} \text { ton }\right)\end{array}$ & 311.39 & 23329.34 & 7724.44 \\
\hline Energy for civilian ( $10^{4}$ ton $)$ & 225.49 & 16893.66 & 5593.56 \\
\hline Water for industry ( $10^{9}$ ton $)$ & 2.39 & 237.97 & 47.01 \\
\hline Water for civilian ( $10^{9}$ ton $)$ & 1.31 & 130.88 & 25.08 \\
\hline Labor ( $10^{4}$ persons $)$ & 470.23 & 1973.30 & 667.80 \\
\hline Technology ( $10^{4}$ persons $)$ & 4.21 & 179.67 & 78.31 \\
\hline Education ( $10^{9}$ yuan $)$ & 2598.95 & 59.10 & 744.70 \\
\hline Health $\left(10^{9}\right.$ yuan $)$ & 3873.63 & 102.80 & 896.81 \\
\hline Environment ( $10^{9}$ yuan $)$ & 0.36 & 141.64 & 19.95 \\
\hline $\begin{array}{l}\text { Gross domestic product } \\
\qquad\left(10^{4} \text { yuan }\right)\end{array}$ & 1018.62 & 67809.85 & 16895.05 \\
\hline Waste gas ( $10^{4}$ ton $)$ & 2.20 & 182.73 & 71.77 \\
\hline Wastewater ( $10^{9}$ ton $)$ & 19997 & 905082 & 21.57 \\
\hline Wastewater treated $\left(10^{9} \mathrm{~m}^{3}\right)$ & 17827.36 & 81457.82 & 19.41 \\
\hline Waste gas treated ( $10^{4}$ ton $)$ & 0.41 & 40.20 & 15.79 \\
\hline Green rate $(\%)$ & 49.1 & 25.9 & 37.9 \\
\hline
\end{tabular}
Statistical Yearbook on the Environment, and China Statistical Yearbook on Science and Technology.

In this study, we divide China into eight regions according to $\mathrm{Yu}$ et al. [27]. Table 2 shows the regional division in detail (Taiwan, Hong Kong, Macau, and Tibet are excluded for lack of data).
Table 1. Statistical description.

Table 2. Regional division in China.

\begin{tabular}{|c|c|}
\hline Region & Provinces \\
\hline Northeast (N) & Liaoning, Jilin, Heilongjiang \\
\hline North coast (NC) & $\begin{array}{c}\text { Beijing, Tianjin, Hebei, } \\
\text { Shandong }\end{array}$ \\
\hline East coast (EC) & Shanghai, Jiangsu, Zhejiang \\
\hline Middle Yellow River (YR) & $\begin{array}{c}\text { Shaanxi, Shanxi, Henan, } \\
\text { Inner Mongolia }\end{array}$ \\
\hline Middle Yangtze River (ytr) & $\begin{array}{c}\text { Hubei, Hunan, Jiangxi and } \\
\text { Anhui }\end{array}$ \\
\hline Southwest (S) & $\begin{array}{c}\text { Yunnan, Guizhou, Sichuan } \\
\text { and Chongqing }\end{array}$ \\
\hline Northwest (NW) & $\begin{array}{c}\text { Gansu, Qinghai, Ningxia, } \\
\text { Xinjiang }\end{array}$ \\
\hline
\end{tabular}

\section{Results and discussion}

Results

Fig. 2a shows the eco-efficiency in China during 2008 to 2014. It shows a slow upward trend before 2014 and a significant upward trend after 2014. The economic part (Fig. 2b) shows a similar changed trend with the eco-efficiency as well as society (Fig. 2c). However, the environment part (Fig. 2d) shows a fluctuant trend from 2008 to 2014. A downward trend occurred from 2009 to 2011 and then an upward trend appeared after 2011. 
Fig. 3a) shows the eco-efficiency of eight regions as well as China. We can find that the eco-efficiency of each region shows an upward trend, especially in the east coast, south coast, north, and northwest. The north region shows a significant upward trend since 2011 as well as the northwest since 2012. However, the regional differences are also significant. There are four regions whose eco-efficiency are below the national average.

a)

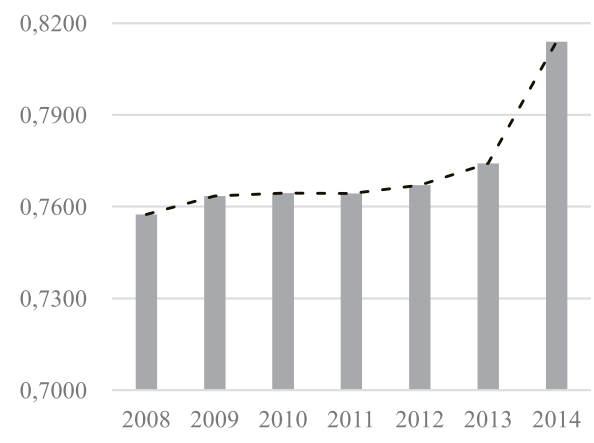

b) $\quad 0,8700$

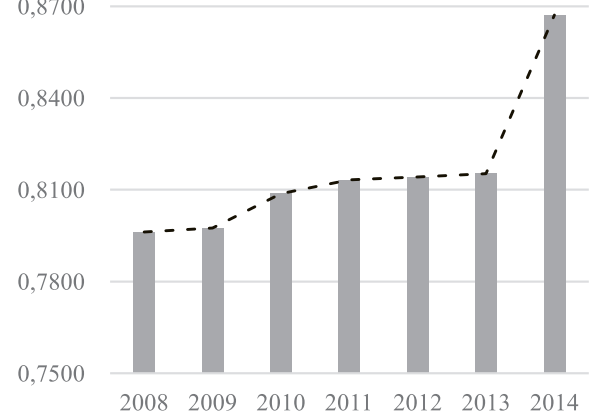

c)

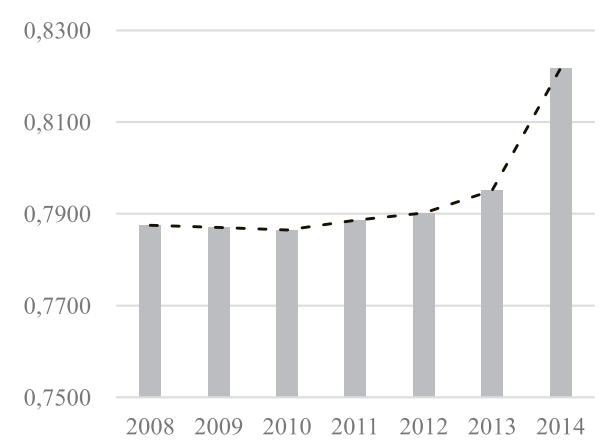

d)

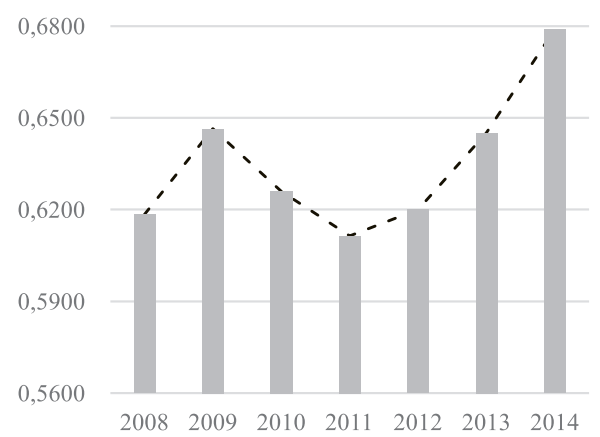

Fig. 2. a) Eco-efficiency of China, b) efficiency of green economy, c) efficiency of green society, d) efficiency of green environment. a)

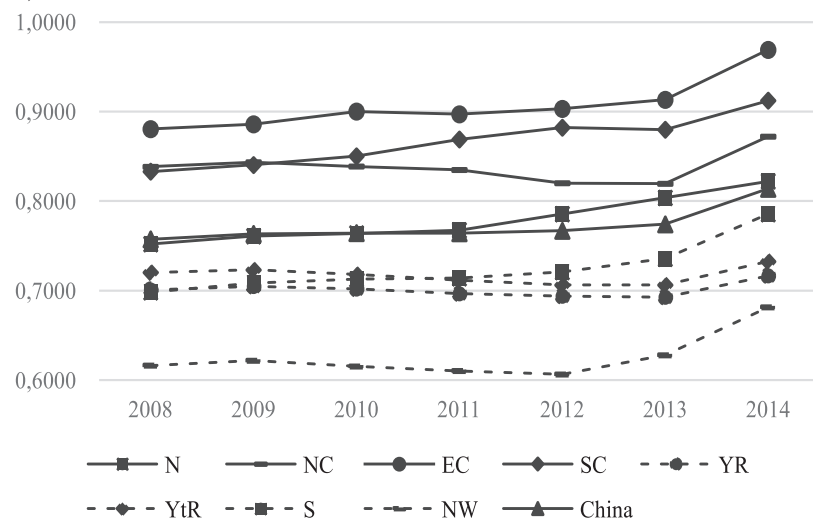

b)

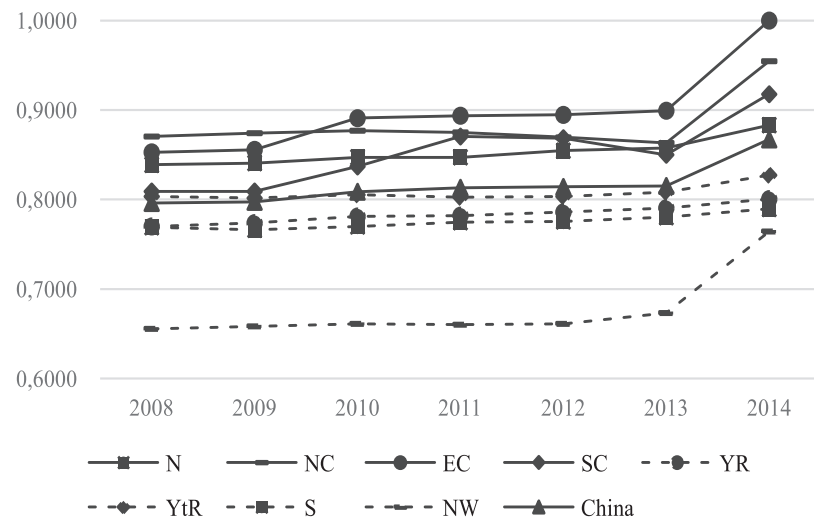

c)

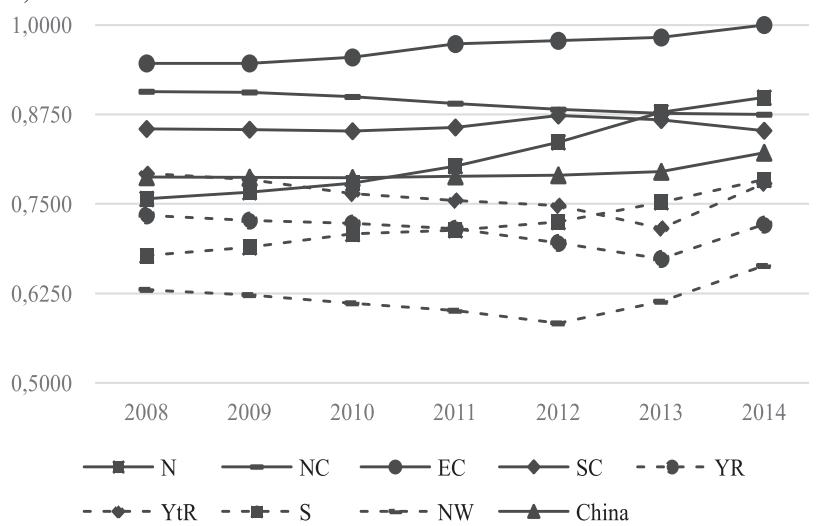

d)

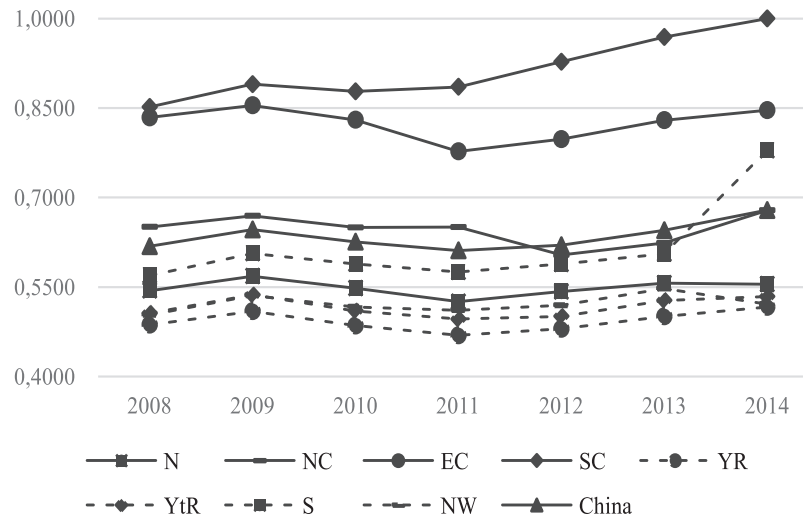

Fig. 3. a) Eco-efficiency in each region, b) efficiency of green economy in each region, c) efficiency of green society in each region, d) efficiencies of green environments in each region. 
The eco-efficiency of the northwest is still especially much lower than that of other regions.

On the economic front, there is a similar situation with that in Fig. 3a). In Fig. 3b), we can find that the economy in several regions that includes the east coast, the south coast, and the north coast show significant changes while other regions show a steady upward trend. The economy of the northwest is still much lower than that of other regions.

On the social front (Fig. 3c), the societies of different regions are diversified in that the east coast, the north, and the southwest present a sharp uptrend while other regions show a declining trend. The society in the northwest showed a significant increasing trend after 2012.

On the environmental front (Fig. 3d), the environment of the east coast and the south coast are much higher than those of other regions. A significant upward trend in the south coast was presented after 2010, while a fluctuant situation, which is a declining trend before 2011 as well as an increasing trend after 2011 in the east coast, was presented. However, it is worth noting that the environment in other regions are still fairly low and the effect of environmental protection was not obvious.

\section{Discussion}

Across the country as a whole, the improvement of eco-efficiency of China mainly comes from the economy and economic development and social progress. First, China worked hard to transform the economic development pattern, including optimizing resource allocation, industrial transformation, and upgrading, improving productivity and resource saving in order to improve the quality of economic development. Therefore, China's economy has maintained steady and rapid growth. Second, livelihood issues had gained more attention. The government increased investment in education and health care. The expenditure on education was nearly 500 billion dollars, and its share in GDP was over 4.5 percent in 2013. Similar cases had been reported in residents' health care. Third, the government encouraged residents to save energy by ladder price for electricity and water, and gave subsidies to residents who used cleaner energy (new energy vehicles and solar-powered residential building). However, insufficient investment in rural infrastructure, especially in waste treatment, led to low environmental levels in China.

Regionally, the level of eco-efficiency mainly relies on economic development. The regions with higher economic development could achieve higher ecoefficiency. In developed regions, the local government had sufficient funds to improve urban and rural infrastructure and give more financial support to induct innovation of the enterprise and encourage enterprise and residents to save energy and resources. Hence, these regions finally could get better performance on ecoefficiency. On the economic front, some regions (the east coast, the north coast, the south coast, and the northeast) have more advanced production technology and almost achieved industrial transformation and upgrading. In these regions, enterprises could achieve higher economic efficiency than enterprises in other regions through supplying higher added value production. For those poor regions the local economy only relied on a large amount of basic resource consumption. This mode of production also produces a lot of waste emissions due to outdated technology. On the social front, the north, the east coast, and the southwest always increase investment in livelihood that included enlarging educational funds, enhancing hospital capacity, and extending health insurance coverage. The local government also implemented a lot of policies to promote clean energy to society. On the environmental front, the east coast and the south have better performance on infrastructure construction. The local government has built a large number of sewage treatment plants and installed a large number of waste gas treatment for plants through subsidies. Moreover, there is a higher level of urban greening for a higher level of urbanization in the regions. According to the analysis, we find that environmental protection still lags behind and is of lower efficiency compared to the other two aspects. Economic development is still the main driving force in improving ecological construction.

\section{Conclusions}

This study assessed the effects of ecological construction in China. We find that eco-efficiency in China is still low. Economic development will be the core strategy for each region in the future. At the same time, the government must pay more attention to environmental protection. The government needs to take the following measures:

1) Poor areas should accelerate industrial transformation and upgrading. Enterprises in these regions should improve their innovation ability and strengthen exchanges and cooperation with enterprises in developed regions.

2) The government continues to increase investment in education. The central and local governments should set up special funds to encourage universities to conduct basic research as well as promote the transformation of innovation to enterprises and residents.

3) The government continue to promote urbanization as well as improve rural infrastructure. In rural regions, the local government should increase funds to build waste treatment plants and sewage treatment facilities, and encourage rural residents to use clean energy. At the same time, the government should strengthen public transport in rural regions and promote production centralization. 
4) We will increase environmental protection, especially environmental monitoring. Environmental management departments in each region should establish environmental monitoring and alarm systems.

\section{Acknowledgements}

This research is supported by the National Natural Science Foundation of China (71703171) and the Natural Science Foundation of Hunan Province (2018JJ3889).

\section{Conflict of Interest}

The authors declare no conflict of interest.

\section{References}

1. DESIMONEL. D., POPOFF F. Eco-Efficiency: The Business Link to Sustainable Development, The MIT Press: Massachusetts, USA, 1, 100, 2000.

2. KICHERER. A., SCHALTEGGER. S., TSCHOCHOHEI. H., POZO. B., Eco-efficiency, International Journal of Life Cycle Assessment, 12 (7), 537, 2007.

3. KORHONEN P.J., LUPTACIK M. Eco-efficiency analysis of power plants: An extension of data envelopment analysis, European Journal of Operational Research, 154 (2), 437, 2004

4. COTE R., BOOTH A., LOUIS B., Eco-efficiency and SMEs in Nova Scotia, Canada, Journal of Cleaner Production, 14 (6-7), 542, 2006.

5. AOE T. Eco-efficiency and ecodesign in electrical and electronic products, Journal of Cleaner Production, 15 (15), 1406, 2007.

6. PARK P.J., TAHARA K. Quantifying producer and consumer-based eco-efficiencies for the identification of key ecodesign issues, Journal of Cleaner Production, 16 (1), 95, 2008.

7. PAGAN B., PRASAD P. The Queensland food ecoefficiency project: reducing risk and improving competitiveness, Journal of Cleaner Production, 15 (8-9), 764, 2007.

8. PARK P.J., TAHARA K., INABA A. Product qualitybased eco-efficiency applied to digital cameras, Journal of Environmental Management, 83 (2), 158, 2007.

9. VAN BERKEL. R., Eco-efficiency in the Australian minerals processing sector, Journal of Cleaner Production, 15 (8), $772,2007$.

10. BASSET-MENS C., LEDGARD S., BOYES M., Eco-efficiency of intensification scenarios for milk production in New Zealand, Ecological Economics, 68 (6), 1615, 2009.

11. VAN CANEGHEM J., BLOCK B., VAN HOOSTE H., VANDECASTEELE C., Eco-efficiency trends of the
Flemish industry: decoupling of environmental impact from economic growth, Journal of Cleaner Production, 18 (14), 1349, 2010.

12. WANG Y., LIU J., HANSSON L., ZHANG K., WANG R. Implementing stricter environmental regulation to enhance eco-efficiency and sustainability: a case study of Shandong Province's pulp and paper industry, China, Journal of Cleaner Production, 19 (4), 303, 2011.

13. FUJII H., MANAGI S. Determinants of eco-efficiency in the Chinese industrial sector, Journal of Environmental Sciences, 25 (S1), S20, 2013.

14. LONG X., ZHAO X., CHENG F., The comparison analysis of total factor productivity and eco-efficiency in China's cement manufactures, Energy Policy, 81, 61, 2015.

15. BAI Y., DENG X., JIANG S., ZHANG Q., WANG Z. Exploring the relationship between urbanization and urban eco-efficiency: Evidence from prefecture-level cities in China, Journal of Cleaner Production, 2017, https://doi. org/10.1016/j.jclepro.2017.11.115

16. LI Z., OUYANG X., DU K., ZHAO Y. Does government transparency contribute to improved eco-efficiency performance? An empirical study of 262 cities in China, Energy Policy, 110, 79, 2017.

17. CHEN C. A network-DEA model with new efficiency measures to incorporate the dynamic effect in production networks, European Journal of Operational Research, 194 (3), 687, 2009.

18. FUKUYAMA H., MIRDEHGHAN S. Identifying the efficiency status in network DEA, European Journal of Operational Research, 220(1), 85, 2012.

19. FARE R., GROSSKOPF S. Productivity and intermediate products: A frontier approach, Economics Letters, 50 (1), 65, 1996.

20. FARE R., GROSSKOPF S. Network DEA, SocioEconomic Planning Sciences, 34 (1), 35, 2000.

21. SEXTON T., LEWIS H. Two-Stage DEA: An Application to Major League Baseball, Journal of Productivity Analysis, 19 (2-3), 227, 2003.

22. SEIFORD L., ZHU J. Profitability and Marketability of the Top 55 U.S. Commercial Banks, Management Science, 45 (9), 1270, 1999.

23. KAO C., HWANG S. Efficiency measurement for network systems: IT impact on firm performance, Decision Support Systems, 48 (3), 437, 2010.

24. CHODAKOWSKA E., NAZARKO J. Network DEA Models for Evaluating Couriers and Messengers, Procedia Engineering, 182, 106, 2017.

25. TONE K., TSUTSUI M. Network DEA: A slacks-based measure approach, European Journal of Operational Research, 197 (1), 243, 2009.

26. COOPER W., TONE K., SEIFORD L. Data Envelopment Analysis: A Comprehensive Text with Models, Applications References, and DEA-Solver Software with Cdrom, Kluwer Academic Publishers, 52 (12), 145, 1999.

27. YU Y., ZHU W., SHI Q., ZHANG Q. Network-like DEA approach for environmental assessment: Evidence from U.S. manufacturing sectors, Journal of Cleaner Production, 139, 277, 2016 